\title{
Physical Fitness in Older People Recently Diagnosed with Cognitive Impairment Compared to Older People Recently Discharged from Hospital
}

\author{
Karin Hesseberg ${ }^{a, b} \quad$ Astrid Bergland $^{a} \quad$ Elisabeth Rydwik ${ }^{c, d}$ \\ Therese Brovold ${ }^{a}$ \\ a Division of Physiotherapy, Oslo and Akershus University College of Applied Sciences, \\ and ${ }^{\mathrm{b}}$ Diakonhjemmet Hospital, Oslo, Norway; ${ }^{\mathrm{C}}$ Division of Physiotherapy, Department \\ Neurobiology Care Sciences and Society, Karolinska Institutet, Huddinge, and \\ ${ }^{d}$ FOU nu, Jakobsbergs Hospital, Stockholm County Council, Järfälla, Sweden
}

Key Words

Mild cognitive impairment · Dementia · Hospitalization · Aging · Independent living

\section{Abstract}

Background/Aims: There is evidence of an association between cognitive function and physical fitness. The aim of this study was to compare physical fitness in patients with cognitive impairment with a group of older people recently discharged from hospital. Methods: A cross-sectional study with 98 patients recently diagnosed with cognitive impairment and 115 patients recently discharged from hospital. Associations between the study group variable and different components in the Senior fitness test were examined, controlling for demographic factors and comorbidity. Results: The group recently diagnosed with cognitive impairment indicated poorer results on three of six physical fitness components $(p<0.05)$. Conclusion: Older adults with cognitive impairment are in need of individually tailored physical activity programs to increase the level of physical fitness.

\section{Introduction}

Older people are the fastest growing group in the world, and maintaining physical independence and good quality of life among older adults are important goals of clinical medicine and public health [1]. Research shows that physical fitness is closely related to health-related quality of life among healthy older people [2], among older people with chronic disease [3] 
and among older people with dementia [4]. Greater physical fitness is essential to carry out tasks and to participate and enjoy social and cultural life [1]. Longitudinal studies suggest that preserving high cardiorespiratory endurance through lifelong participation in physical activities may protect against cognitive decline among older people. Furthermore, physical activity may even attenuate the progression of dementia among older people with mild cognitive impairment (MCI) [5, 6]. Therefore, from the perspective of costs, health and social policy as well as from the personal perspective, prevention of decline in physical fitness is important since small differences in function and dependence are reported to be associated with large differences in care costs, informal caregiving costs as well as the older person's independence and wellbeing $[2,7,8]$. Being able to live at home as long as possible is a political goal and is also seen as a right [1].

However, as individuals get older, they are predisposed to chronic disease, cognitive impairment and hospitalization which have direct impact on their level of physical function and their ability to stay active [9-11]. Especially, cognitive decline has been associated with lower levels of physical fitness [12] and may be a serious threat to older people's independence and quality of life [13].

Physical fitness is considered to be a component of physical function and can be defined as the capacity to perform daily activities safely and independently without fatigue [14]. The concept is multidimensional and includes muscle strength, cardiorespiratory endurance, flexibility, balance and agility/mobility [15]. Successful performance in activities of daily living in complex environments requires higher levels of physical fitness and cognitive abilities.

Previous research has identified several risk factors for decline in physical fitness among older people, which include increasing age, chronic disease, admission to hospital and reduction in cognitive function such as memory and executive function $[3,16-19]$. Hospitalization and acute medical illness is often associated with poor physical fitness because of the cumulative effects of illness, medication and fatigue, on cardiopulmonary and musculoskeletal functioning $[3,20,21]$. There is strong evidence of a consistent association between cognitive function and different aspects of physical fitness related to independent living such as gait speed, mobility, balance and muscle strength [12, 17, 22-34]. As mentioned above, maintaining adequate levels of aerobic fitness and walking endurance can avoid unnecessary functional dependency in older people with and without cognitive impairment, and may even be a protective factor for the development and progression of cognitive decline [35-40]. However, most studies concerning associations between cognitive function and physical fitness components compare physical fitness in older people with cognitive impairment with healthy older people without cognitive impairment [22, 28, 30, 32, 34, 41]. To get a broader picture of the level of physical fitness among older people with cognitive impairment, it may be of importance to compare the level of physical fitness between two groups at high risk for inactivity and functional decline. Chronic diseases in combination with inactivity are two important reasons for decline in physical fitness among older people [42]. In a recent study, we showed that older people with different comorbidities recently discharged from hospital due to an acute medical disease, had low levels of physical fitness and physical activity [3]. Research shows that impaired cognition and reduced cognitive abilities can affect the person's ability to participate in leisure time activity [43], and it is reported that older people with cognitive decline have low levels of physical activity [31]. Therefore, based on the results from previous studies, it is reasonable to believe that older people with MCI have even lower levels of physical fitness than older people recently discharged from hospital. By comparing two groups of older persons with different health problems, we wanted to highlight how affected physical fitness can be in older people with cognitive impairment. Early detection is essential in order to prevent further decline through physical activity interventions and reha- 
Hesseberg et al.: Physical Fitness in Older People Recently Diagnosed with Cognitive

bilitation strategies [44-46]. A comprehensive profiling of physical fitness of older people might assist researchers and health-care practitioners in designing more comprehensive, targeted exercise interventions.

To our knowledge, there is a knowledge gap related to the differences in performance in physical fitness in older people recently diagnosed with cognitive impairment and older people with chronic disease recently discharged from hospital who did not have severe cognitive problems, and who lived in their own homes.

Thus, the aim of this study was to compare patients with cognitive impairment with a group of older people recently discharged from hospital in relation to different components of physical fitness when controlling for demographic factors. This study aimed at adding new knowledge regarding clinical impairments of physical fitness in those who are diagnosed with cognitive impairments. Our hypothesis was that when compared to older persons with comorbidities recently discharged from hospital, patients with MCI have lower levels of physical fitness even when controlling for demographic factors.

\section{Methods}

\section{Participants and Procedure}

The sample includes baseline data from two study settings and has a cross-sectional design. The first study setting (study 1 ) included older people $\geq 65$ years of age diagnosed with cognitive impairment. The term cognitive impairment in this study includes MCI and dementia. The participants were recruited from four memory clinics in Norway (essentially in Oslo area) after an initial examination regarding cognitive impairment and possible dementia, assessed in accordance with a standard examination protocol [47, 48]. Physicians at the memory clinics diagnosed their patients, and they were included in the study if they were registered in 'The Patient Registry for Dementia Assessment in Norway' and were diagnosed with cognitive impairment; either MCI or dementia. The ICD-10 classification was used when diagnosing dementia, and the Winblad criteria were used when diagnosing MCI [49]. Physical fitness was assessed by an experienced physiotherapist less than 2 months after the diagnosis of cognitive impairment.

The second study setting (study 2) included baseline data from a randomized controlled aerobic exercise intervention trial, including patients discharged from hospital. Participants were $\geq 70$ years of age and were recruited whilst resident in the hospital (Oslo area) due to an acute medical event. Physical fitness and cognitive tests were assessed by an experienced physiotherapist at baseline 2-4 weeks after discharge from hospital. Participants were excluded if they had cognitive impairment assessed as a score of $<24$ on Mini-Mental State Examination $[3,50]$.

Inclusion criteria in both study settings were that they were living in the community with no known chronic disease with an expected lifespan of $<1$ year.

\section{Outcome Variables}

Senior Fitness Test

The main outcome was the Senior fitness test (SFT), which is a widely used standardized and safe assessment for providing information about physical fitness in older people $[15,51$, 52]. Physical fitness is a multidimensional concept, and the SFT was designed to assess underlying physical parameters associated with functional mobility such as muscle strength, cardiorespiratory endurance, flexibility, balance and agility/mobility [14]. The SFT item scores create a profile of these major fitness components associated with independent functioning [15]. 
Hesseberg et al.: Physical Fitness in Older People Recently Diagnosed with Cognitive

The SFT assessments were made in the order presented: chair stand test for lower body muscle strength (number within $30 \mathrm{~s}$ ); arm curl test for upper body muscle strength (number within $30 \mathrm{~s}$ ); chair sit and reach test (CSR) for lower body flexibility (distance between fingers and toe); back scratch test for upper body flexibility (distance between the two third fingers); 2.45-meter up-and-go test (Up\&go) for power, speed, agility and dynamic balance (time to rise, walk $2.45 \mathrm{~m}$ and return to the chair), and 6-min walk test to measure cardiovascular endurance (distance walked in $6 \mathrm{~min}$ ). More detailed descriptions are presented in the manual [15]. SFT is a reliable test battery for assessing physical fitness in older people $\geq 60$ years old, including older people with cognitive impairment $[15,53]$.

\section{Cognitive Testing}

Cognitive tests included three cognitive tests which were a part of the standard examination protocol in 'The Patient Registry for Dementia Assessment in Norway': (1) The Clock drawing test (clock test) with scoring instructions from 0 to 5 [54]. Test scores of 4-5 indicate a normal score according to the scoring procedure of Shulman [54]. The clock test addresses visual perception, constructional and executive difficulties [55]. (2) The Trail making test A and B (TMTA and B) are timed in seconds and categorized into four categories based on normative age-adjusted time intervals [56]. TMTA was used to provide information about attention and speed, and TMTB was used to provide information about executive function and mental flexibility (set shift) [55]. (3) The 10-word list learning test from the CERAD (Consortium to establish a registry for Alzheimer's disease) consists of a list of 10 words presented three times. The participants were asked to recall the words. Scores of 0-30 were used to measure the total number of correct words learned (10-word recall), and scores of $0-10$ were used to measure the correct words recalled after 5 min of distraction (10-word delayed) [57]. The patients referred to a memory clinic for an initial examination regarding cognitive impairment and possible dementia were further assessed in accordance with a standard examination protocol. The whole examination protocol has been described elsewhere [47]. Testing was conducted by experienced nurses, occupational therapists and physicians at the memory clinics, and by experienced physiotherapists at the hospitals.

\section{Statistical Analysis}

The characteristics of the sample are presented with the mean and standard deviation (SD) for continuous variables and percentages for categorical variables. Statistical differences between the two study groups were calculated using the $\chi^{2}$ test for categorical variables and independent samples t test for continuous variables. Univariate linear regression was used to show the associations between the different components of SFT, the variable of study group (study group 1 and 2), and demographic factors such as age, gender, marital status, comorbidity and BMI. Statistically significant variables in the univariate analysis were included in a subsequent multiple regression analysis (enter method) to examine the association with the study group variable and the different components of SFT in order to control for confounders. Analyses of multicollinearity were checked to detect any high level of association between independent variables and covariates. Residual plots were inspected, and if the model assumptions were violated, a sensitivity analysis was performed to test the robustness of the results. Statistical analyses were performed with the Statistical Package for Social Science (SPSS), version 21 (SPSS Inc., Chicago, Ill., USA). p values $<0.05$ were considered statistically significant, and all tests were two sided.

\section{Ethics}

Both study settings were approved by the Regional Committee for Medical Research Ethics in South-Eastern Norway. The participants were given oral and written information 
Hesseberg et al.: Physical Fitness in Older People Recently Diagnosed with Cognitive Impairment Compared to Older People Recently Discharged from Hospital

Table 1. Demographic characteristics and performance in cognitive tests in the whole sample, and divided by study group

\begin{tabular}{|c|c|c|c|c|c|}
\hline & $\mathrm{n}$ & All & $\begin{array}{l}\text { Study group } 1 \\
(\mathrm{n}=98)^{\mathrm{a}}\end{array}$ & $\begin{array}{l}\text { Study group } 2 \\
(\mathrm{n}=115)^{\mathrm{b}}\end{array}$ & $\begin{array}{l}\text { Between-group } \\
\text { differences, } \mathrm{p}^{\mathrm{c}}\end{array}$ \\
\hline Age, years & 213 & $78.3(6.3)$ & $78.8(7.4)$ & $78.0(5.2)$ & 0.370 \\
\hline Gender, \% women & 213 & 58 & 54 & 61 & 0.390 \\
\hline Walking aid, \% no walking aid & 212 & 88 & 82 & 93 & 0.021 \\
\hline Living alone, $\%$ yes & 213 & 48 & 40 & 55 & 0.041 \\
\hline Comorbidity & 196 & $2.1(1.3)$ & $1.6(1.3)$ & $2.5(1.1)$ & $<0.001$ \\
\hline BMI & 212 & $25.6(4.8)$ & $23.8(3.9)$ & $27.0(4.9)$ & $<0.001$ \\
\hline \multicolumn{6}{|l|}{ Cognitive tests } \\
\hline Clock test, $1-5$ & 212 & $3.9(1.4)$ & $3.4(1.7)$ & $4.4(0.8)$ & $<0.001$ \\
\hline TMTA, s & 211 & $73.4(43.7)$ & $90.4(55.0)$ & $58.7(21.9)$ & $<0.001$ \\
\hline Unable to complete, $\%$ & & 0.5 & 1 & 0 & $<0.001$ \\
\hline Able to complete, but score $<2$ SD, $\%$ & & 22 & 37 & 10 & \\
\hline Time between 1 and 2 SD, \% & & 34 & 31 & 36 & \\
\hline Time better than 1 SD, $\%$ & & 44 & 32 & 54 & \\
\hline TMTB, s & 210 & $196.1(84.8)$ & $244.7(78.1)$ & $154.4(66.4)$ & $<0.001$ \\
\hline Unable to complete, $\%$ & & 24 & 52 & 0 & $<0.001$ \\
\hline Able to complete, but score $<2 \mathrm{SD}, \%$ & & 14 & 14 & 14 & \\
\hline Time between 1 and 2 SD, \% & & 15 & 11 & 18 & \\
\hline Time better than 1 SD, $\%$ & & 47 & 23 & 68 & \\
\hline 10 -word recall & 210 & $16.0(5.3)$ & $2.3(4.5)$ & $19.1(3.7)$ & $<0.001$ \\
\hline 10-word delayed recall & 209 & $4.2(2.9)$ & $1.9(2.1)$ & $6.1(2.0)$ & $<0.001$ \\
\hline \multicolumn{6}{|l|}{ Physical fitness } \\
\hline \multicolumn{6}{|l|}{ SFT } \\
\hline Chair stand & 213 & $9.8(3.8)$ & $9.4(4.2)$ & $10.2(3.4)$ & 0.137 \\
\hline Arm curl & 212 & $13.4(3.7)$ & $13.1(3.8)$ & $13.6(3.7)$ & 0.338 \\
\hline CSR & 212 & $-7.1(13.2)$ & $-12.0(12.6)$ & $-2.9(12.4)$ & $<0.001$ \\
\hline Backscratch & 212 & $-15.4(12.4)$ & $-16.4(12.2)$ & $-14.5(12.5)$ & 0.267 \\
\hline Up\&go test & 212 & $7.9(3.1)$ & $9.0(3.7)$ & $6.9(2.0)$ & $<0.001$ \\
\hline 6 -min walk test & 212 & 439 (119) & 420 (123) & 453 (115) & 0.054 \\
\hline
\end{tabular}

Data are presented as mean (SD) or as stated. ${ }^{a}$ Recently diagnosed with cognitive impairment. ${ }^{b}$ Recently discharged from hospital because of a recent acute medical event without cognitive impairment. ${ }^{c}$ t test and $\chi^{2}$ test; $p$ value $<0.05$ was considered statistically significant.

about the study and signed a written informed consent before taking part. In the group of patients with cognitive impairment, a physician at the memory clinic assessed if the participants were able to give their consent before they were included in the study. If they were not able to give their consent, they were excluded from the study.

\section{Results}

Two hundred and thirteen community-dwelling older persons ( 90 men and 123 women) diagnosed with cognitive impairment ( $n=98,59$ with MCI, 39 with dementia) or recently discharged from hospital because of a recent acute medical event, and without cognitive impairment $(n=115)$ participated in this study. Table 1 shows the characteristics of the whole sample - study group 1 and study group 2 . Study group 1 performed worse in the fitness components CSR, Up\&go test and 6-min walk test, compared to study group 2 ( $\mathrm{p}<$ $0.001,<0.001$ and 0.054 , respectively). Our results demonstrated that study group 1 had statistically significant worse score in all of the cognitive tests compared to study group 2 (the clock test, TMTA and B, and 10-word recall and delayed tests; $\mathrm{p}<0.001$ ). In addition, there 
Hesseberg et al.: Physical Fitness in Older People Recently Diagnosed with Cognitive Impairment Compared to Older People Recently Discharged from Hospital

Table 2. Linear and multiple regression analysis of associations between the components of physical fitness measured with SFT and demographic variables and comorbidity

\begin{tabular}{|c|c|c|c|c|c|}
\hline \multirow{2}{*}{$\begin{array}{l}\text { Dependent and independent variables } \\
\text { and covariates }\end{array}$} & \multicolumn{2}{|l|}{ Univariate analysis } & \multicolumn{3}{|l|}{ Multiple analysis $^{\mathrm{a}}$} \\
\hline & B $(95 \%$ CI $)$ & $\mathrm{p}$ value & B $(95 \% \mathrm{CI})$ & $\mathrm{p}$ value & $\mathrm{R}^{2}$ \\
\hline Chair sit and reach test & & & & & 0.220 \\
\hline Study group (ref. = group 2) & $-9.11(-12.50 ;-5.72)$ & $<0.001$ & $-8.27(-11.53 ;-5.01)$ & $<0.001$ & \\
\hline Age & $-0.20(-0.48 ; 0.09)$ & 0.173 & $-0.25(-0.51 ; 0.01)$ & 0.064 & \\
\hline Gender (ref. = man) & $8.59(5.14 ; 12.03)$ & $<0.001$ & $8.20(4.63 ; 11.78)$ & $<0.001$ & \\
\hline Married/cohabitant (ref. = yes) & $4.62(1.07 ; 8.16)$ & 0.011 & $0.51(-3.09 ; 4.11)$ & 0.779 & \\
\hline Comorbidity & $0.34(-1.10 ; 1.79)$ & 0.639 & & & \\
\hline BMI & $0.17(-0.21 ; 0.54)$ & 0.384 & & & \\
\hline Up\&go test & & & & & 0.317 \\
\hline Study group (ref. = group 2) & $2.07(1.27 ; 2.86)$ & $<0.001$ & $2.71(1.93 ; 3.50)$ & $<0.001$ & \\
\hline Age & $0.16(0.09 ; 0.22)$ & $<0.001$ & $0.15(0.09 ; 0.21)$ & $<0.001$ & \\
\hline Gender (ref. = man) & $1.15(0.31 ; 1.98)$ & 0.007 & $0.74(-0.17 ; 1.50)$ & 0.055 & \\
\hline Married/cohabitant (ref. = yes) & $0.65(-0.18 ; 1.49)$ & 0.125 & & & \\
\hline Comorbidity & $0.39(0.05 ; 0.72)$ & 0.024 & $0.77(0.47 ; 1.08)$ & $<0.001$ & \\
\hline BMI & $-0.07(-0.16 ; 0.01)$ & 0.098 & & & \\
\hline 6-min walk test & & & & & 0.382 \\
\hline Study group (ref. = group 2) & $-32.26(-65.09 ; 0.57)$ & 0.054 & $-82,47(-112,95 ;-51,99)$ & $<0.001$ & \\
\hline Age & $-6.25(-8.81 ;-3.69)$ & $<0.001$ & $-7.32(-9.62 ;-5.02)$ & $<0.001$ & \\
\hline Gender (ref. = man) & $-69.84(-101.53 ;-38.15)$ & $<0.001$ & $-52.39(-80.83 ;-23.95)$ & $<0.001$ & \\
\hline Married/cohabitant (ref. = yes) & $-31.50(-64.14 ; 1.14)$ & 0.059 & & & \\
\hline Comorbidity & $-28.07(-40.78 ;-15.36)$ & $<0.001$ & $-31.62(-43.26 ;-20.05)$ & $<0.001$ & \\
\hline BMI & $-3.63(-7.07 ;-0.19)$ & 0.039 & $-7.31(-10.55 ;-4.07)$ & $<0.001$ & \\
\hline
\end{tabular}

$\mathrm{B}=$ Unstandardized coefficients; $\mathrm{CI}=$ confidence interval; $\mathrm{R}^{2}=$ explained variance of the model. ${ }^{\text {a }}$ Adjustment for variables significantly associated with the actual component of physical fitness in the univariate analyses.

were differences between the groups regarding use of walking aid, BMI, comorbidity and marital status $(\mathrm{p}<0.001)$ (table 1$)$.

The results from the univariate and multiple regression analyses regarding the associations between the components of physical fitness and variables of demographic and comorbidity are presented in table 2 . The 10 -word delayed test were excluded due to high correlation $(>0.70)$ with the 10 -word recall test and the study group variable. The independent variable 'study group', was still significant in the multiple analyses. The results regarding the associations between the components of physical fitness and 'Study group' showed that being in study group 1 indicated poorer results on the physical fitness components CSR, Up\&go test and 6-min walk test $[B=-6.70(p=0.004), B=2.09(p<0.001)$ and $B=-43.77(p=0.030)$ respectively].

\section{Discussion}

In this study, we compared the level of physical fitness between a group of patients with cognitive impairment and a group of older people with chronic disease recently discharged from hospital. The main findings showed that older people with cognitive impairment performed significantly worse on the physical fitness tests CSR, Up\&go test and 6-min walk test compared to older people recently discharged from hospital, even when controlling for demographic factors and comorbidity. These results show that being diagnosed with $\mathrm{MCI}$ or dementia is associated with lower physical fitness, and support previous studies reporting a 
strong negative association between cognitive impairment and different aspects of physical fitness [22, 25, 29, 58-68].

The results support the need for a focus on physical fitness and functioning in older people with MCI and early dementia living in the community. Maintaining adequate physical fitness among people who are diagnosed with MCI and dementia may help them to live longer in their own home and reduce the burden of their care takers. Thus, the results suggest that focus on physical activity and physical fitness after the diagnosis may be of importance.

In line with our results, associations between cognitive function and physical performance have been reported in the areas of gait, aerobic endurance, balance, and fall risk in older adults with normal cognitive function, $\mathrm{MCI}$ and dementia, and they are especially robust in the presence of executive dysfunction [12, 28, 30, 33, 69-72]. Declining executive function may be an early indicator of overall functional decline in older adults, and has been shown to be predictive of functional decline and increased risk for dementia in community-dwelling older adults $[23,26]$. In a prospective study of older women with intact cognition at baseline, executive function decline occurred 3 years prior to memory decline over a 9-year follow-up period, and executive function decline occurred more often than any other cognitive impairment [73]. The combination of reduced physical fitness and executive function may be more predictive of dementia risk; therefore, it has implications for accelerated functional decline, and disability is of importance for participants with cognitive impairment in our study.

The findings in this current study showed significant associations between mobility measured in the Up\&go test as well as in the 6-min walk test and the study group. Intact gait control requires the efficient integration of many neural systems, including motor, sensory and cognitive processes, and cognitive subsystems such as memory, attention and executive function [74].

Even though cognitive impairment cannot be cured at present, decline in physical fitness can be slowed by physical activity interventions. The benefits of exercise and physical activity in delaying physical dependence in an elderly population and among people with cognitive impairment and dementia have been shown in several studies [44, 45, 64, 75-77]. Interventions should be directed to the affected components of physical fitness to initiate individually tailored training programs. Due to lower executive function, several support strategies need to be included. In addition, effective prevention and rehabilitation strategies to maintain functional independency and avoid institutionalization could be established.

Cognitive impairment may influence the older adults' interpretation and reporting of symptoms. This might lead to delays in identification and treatment of new illnesses or exacerbations of existing diseases and to a greater extent influence older people recently diagnosed with cognitive impairment compared to older people with a recent acute medical event. Cognitive impairment may also complicate the use of standard approaches to chronic disease management. Both of these factors may influence physical function. In addition, progression of the disease that underlies cognitive impairment may result in changes in physical function [78].

\section{Limitations}

One limitation of this study was the cross-sectional design. This makes us unable to make conclusions on causality. All observational studies are hampered by residual confounding to various degrees. We have added key health-related confounders (gender, age, comorbidity) which only to a limited degree attenuated the cognitive impairment-physical function association. Furthermore, we recognize that there are other potential factors that could explain the difference in physical fitness between our two study groups such as previous physical activity, medication, motivation and depression. In study group 1, many patients refused to 
participate (around 50\%), and we do not know if they were different from the patients who agreed to participate. They were not asked to give any reason for the refusal. Thus, we were not able to collect systematic data to analyze possible causes or differences between those who agreed and those who did not agree to participate. Our results cannot be generalized to all patients with $\mathrm{MCI}$ or dementia or older people recently discharged from hospital. In study group 2, subjects were enrolled in an intervention trial with an aerobic exercise component; they might therefore be fitter and perhaps more engaged than those who would not have agreed to be part of the intervention. Therefore the associations seen in this study may not be applicable to the overall population of older people recently discharged from hospital.

\section{Conclusion}

In conclusion, this study shows that the level of physical fitness was low among older adults with cognitive impairments compared to older people discharged from hospital. Thus, this study supports that public health initiatives should be designed to reduce passive sedentary behavior in older adults with cognitive impairment. This group is also in need of individually tailored physical activity programs with built-in supportive strategies to counteract the problems with lower executive functions.

\section{References}

1 World Health Organization: Active Ageing, a Policy Framework. Geneva, World Health Organization, 2010.

$>2$ Acree LS, Longfors J, Fjeldstad AS, Fjeldstad C, Schank B, Nickel KJ, Montgomery PS, Gardner AW: Physical activity is related to quality of life in older adults. Health Qual Life Outcomes 2006;4:1-6.

-3 Brovold T, Skelton DA, Bergland A: Association between health-related quality of life, physical fitness and physical activity in older people recently discharged from hospital. J Aging Phys Act 2014;22:405-413.

-4 Telenius EW, Engedal K, Bergland A: Long-term effects of a 12 weeks high-intensity functional exercise program on physical function and mental health in nursing home residents with dementia: a single blinded randomized controlled trial. BMC Geriatr 2015;15:158.

5 Barnes DE, Whitmer RA, Yaffe K: Physical activity and dementia: the need for prevention trials. Exerc Sport Sci Rev 2007;35:24-29.

6 Grande G, Vanacore N, Maggiore L, Cucumo V, Ghiretti R, Galimberti D, Scarpini E, Mariani C, Clerici F: Physical activity reduces the risk of dementia in mild cognitive impairment subjects: a cohort study. J Alzheimers Dis 2014;39:833-839.

7 Spirduso WW, Croninn LD: Exercise dose-response effects on quality of life and independent living in older adults. Med Sci Sports Exerc 2001;33:598-608.

-8 Zhu CW, Leibman C, McLaughlin T, Scarmeas N, Albert M, Brandt J, Blacker D, Sano M, Stern Y: The effects of patient function and dependence on costs of care in Alzheimer's disease. J Am Geriatr Soc 2008;56:14971503.

9 Christensen K, Doblhammer G, Rau R, Vaupel JW: Ageing populations: the challenges ahead. Lancet 2009;374: 1196-1208.

10 Giné-Garriga M, Guerra M, Unnithan V: The effect of functional circuit training on self-reported fear of falling and health status in a group of physically frail older individuals: a randomized controlled trial. Aging Clin Exp Res 2013;25:329-336.

11 Gine-Garriga M, Martin-Borras C, Puig-Ribera A, Martin-Cantera C, Sola M, Cuesta-Vargas A: The effect of a physical activity program on the total number of primary care visits in inactive patients: a 15-month randomized controlled trial. PLoS One 2013;8:e66392.

12 Hesseberg K, Bentzen H, Ranhoff AH, Engedal K, Bergland A: Physical fitness in older people with mild cognitive impairment and dementia. J Aging Phys Act 2016;24:92-100.

13 Barrios H, Narciso S, Guerreiro M, Maroco J, Logsdon R, de Mendonca A: Quality of life in patients with mild cognitive impairment. Aging Ment Health 2013;17:287-292.

$\checkmark 14$ Rikli RE, Jones CJ: Development and validation of a functional fitness test for community-residing older adults. J Aging Phys Act 1999; 7:129-161.

15 Rikli RE, Jones CJ: Senior fitness test manual. Champaign, Human Kinetics, 2001.

16 DiPietro L: Physical activity in aging: changes in patterns and their relationship to health and function. J Gerontol A Biol Sci Med Scis 2001;56:13-22. 
Stuck AE, Walthert JM, Nikolaus T, Bula CJ, Hohmann C, Beck JC: Risk factors for functional status decline in community-living elderly people: a systematic literature review. Soc Sci Med 1999;48:445-469.

18 Warburton DER, Nicol CW, Bredin SSD: Health benefits of physical activity: the evidence. Can Med Assoc J 2006;174:801-809.

19 Warburton DER, Nicol CW, Bredin SSD: Prescribing exercise as preventive therapy. Can Med Assoc J 2006;174: 961-974.

20 de Morton NA, Keating JL, Jeffs K: Exercise for acutely hospitalised older medical patients. Cochrane Database Syst Rev 2007:CD005955.

21 Murphy CL, Sheane BJ, Cunnane G: Attitudes towards exercise in patients with chronic disease: the influence of comorbid factors on motivation and ability to exercise. Postgrad Med J 2011;87:96-100.

$\checkmark 22$ Auyeung TW, Kwok T, Lee J, Leung PC, Leung J, Woo J: Functional decline in cognitive impairment - the relationship between physical and cognitive function. Neuroepidemiology 2008;31:167-173.

23 Blacker D, Lee H, Muzikansky A, Martin EC, Tanzi R, McArdle JJ, Moss M, Albert M: Neuropsychological measures in normal individuals that predict subsequent cognitive decline. Arch Neurol 2007;64:862-871.

-24 Donoghue OA, Horgan NF, Savva GM, Cronin H, O’Regan C, Kenny RA: Association between timed up-and-go and memory, executive function, and processing speed. J Am Geriatr Soc 2012;60:1681-1686.

25 Hsu CL, Nagamatsu LS, Davis JC, Liu-Ambrose T: Examining the relationship between specific cognitive processes and falls risk in older adults: a systematic review. Osteoporos Int 2012;23:2409-2424.

-26 Johnson JK, Lui LY, Yaffe K: Executive function, more than global cognition, predicts functional decline and mortality in elderly women. J Gerontol A Biol Sci Med Sci 2007;62:1134-1141.

27 Lee I-M, Shiroma EJ, Lobelo F, Puska P, Blair SN, Katzmarzyk PT: Effect of physical inactivity on major noncommunicable diseases worldwide: an analysis of burden of disease and life expectancy. Lancet 2012;380: 219-229.

-28 McGough EL, Kelly VE, Logsdon RG, McCurry SM, Cochrane BB, Engel JM, Teri L, Liu-Ambrose TY: Associations between physical performance and executive function in older adults with mild cognitive impairment: gait speed and the timed 'up \& go' test. Phys Ther 2011;91:1198-1210.

29 Muir SW, Gopaul K, Montero Odasso MM: The role of cognitive impairment in fall risk among older adults: a systematic review and meta-analysis. Age Ageing 2012;41:299-308.

-30 Persad CC, Jones JL, Ashton-Miller JA, Alexander NB, Giordani B: Executive function and gait in older adults with cognitive impairment. J Gerontol A Biol Sci Med Sci 2008;63A:1350-1355.

-31 Pettersson AF: Activity level and balance in subjects with mild Alzheimer's disease. Dement Geriatr Cogn Disord 2002;13:213-216.

-32 Pettersson AF, Olsson E, Wahlund LO: Motor function in subjects with mild cognitive impairment and early Alzheimer's disease. Dement Geriatr Cogn Disord 2005;19:299-304.

-33 Tangen GG, Engedal K, Bergland A, Moger TA, Mengshoel AM: Relationships between balance and cognition in patients with subjective cognitive impairment, mild cognitive impairment, and Alzheimer disease. Phys Ther 2014;94:1123-1134.

-34 Takata Y, Ansai T, Soh I, Kimura Y, Yoshitake Y, Sonoki K, Awano S, Kagiyama S, Yoshida A, Nakamichi I, Hamasaki T, Torisu T, Toyoshima K, Takehara T: Physical fitness and cognitive function in an 85-year-old community-dwelling population. Gerontology 2008;54:354-360.

-35 Ahlskog JE, Geda YE, Graff-Radford NR, Petersen RC: Physical exercise as a preventive or disease-modifying treatment of dementia and brain aging. Mayo Clin Proc 2011;86:876-884.

-36 Arnett SW, Laity JH, Agrawal SK, Cress ME: Aerobic reserve and physical functional performance in older adults. Age Ageing 2008;37:384-389.

-37 Hausdorff JM, Buchman AS: What links gait speed and mci with dementia? A fresh look at the association between motor and cognitive function. J Gerontol A Biol Sci Med Sci 2013;68:409-411.

-38 Laurin D, Verreault R, Lindsay J, MacPherson K, Rockwood K: Physical activity and risk of cognitive impairment and dementia in elderly persons. Arch Neurol 2001;58:498-504.

-39 Smith PJ, Blumenthal JA, Hoffman BM, Cooper H, Strauman TA, Welsh-Bohmer K, Browndyke JN, Sherwood A: Aerobic exercise and neurocognitive performance: A meta-analytic review of randomized controlled trials. Psychosom Med 2010;72:239-252.

40 Sofi F, Valecchi D, Bacci D, Abbate R, Gensini GF, Casini A, Macchi C: Physical activity and risk of cognitive decline: a meta-analysis of prospective studies. J Intern Med 2011;269:107-117.

-41 Watson NL, Rosano C, Boudreau RM, Simonsick EM, Ferrucci L, Sutton-Tyrrell K, Hardy SE, Atkinson HH, Yaffe K, Satterfield S, Harris TB, Newman AB: Executive function, memory, and gait speed decline in well-functioning older adults. J Gerontol A Biol Sci Med Sci 2010;65A:1093-1100.

42 Chodzko-Zajko WJ, Proctor DN, Fiatarone Singh MA, Minson CT, Nigg CR, Salem GJ, Skinner JS: Exercise and physical activity for older adults. Med Sci Sports Exerc 2009;41:1510-1530.

-43 Eshkoor SA, Hamid TA, Mun CY, Ng CK: Mild cognitive impairment and its management in older people. Clin Interv Aging 2015;10:687-693.

44 Chodzko-Zajko WJ, Proctor DN, Fiatarone Singh MA, Minson CT, Nigg CR, Salem GJ, Skinner JS: American College of Sports Medicine position stand. Exercise and physical activity for older adults. Med Sci Sports Exerc 2009;41:1510-1530. 
45 Littbrand H, Stenvall M, Rosendahl E: Applicability and effects of physical exercise on physical and cognitive functions and activities of daily living among people with dementia: a systematic review. Am J Phys Med Rehab 2011;90:495-518.

-46 Ngandu T, Lehtisalo J, Solomon A, Levalahti E, Ahtiluoto S, Antikainen R, Backman L, Hanninen T, Jula A, Laatikainen T, Lindstrom J, Mangialasche F, Paajanen T, Pajala S, Peltonen M, Rauramaa R, Stigsdotter-Neely A, Strandberg T, Tuomilehto J, Soininen H, Kivipelto M: A 2 year multidomain intervention of diet, exercise, cognitive training, and vascular risk monitoring versus control to prevent cognitive decline in at-risk elderly people (FINGER): a randomised controlled trial. Lancet 2015;385:2255-2263.

$\checkmark 47$ Braekhus A, Ulstein I, Wyller TB, Engedal K: The memory clinic - outpatient assessment when dementia is suspected. Tidsskrift For Den Norske Lægeforening 2011;131:2254-2257.

-48 Hesseberg K, Bentzen H, Ranhoff AH, Engedal K, Bergland A: Disability in instrumental activities of daily living in elderly patients with mild cognitive impairment and Alzheimer's disease. Dement Geriatr Cogn Disord 2013;36:146-153.

-49 Winblad B, Palmer K, Kivipelto M, Jelic V, Fratiglioni L, Wahlund LO, Nordberg A, Backman L, Albert M, Almkvist O, Arai H, Basun H, Blennow K, De Leon M, DeCarli C, Erkinjuntti T, Giacobini E, Graff C, Hardy J, Jack C, Jorm A, Ritchie K, Van Duijn C, Visser P, Petersen RC: Mild cognitive impairment - beyond controversies, towards a consensus: report of the international working group on mild cognitive impairment. J Intern Med 2004;256: 240-246.

50 Folstein MF, Folstein SE, McHugh PR: 'Mini-mental state': a practical method for grading the cognitive state of patients for the clinician. J Psychiatr Res 1975;12:189-198.

51 DiBrezzo R, Shadden BB, Raybon BH, Powers M: Exercise intervention designed to improve strength and dynamic balance among community-dwelling older adults. J Aging Phys Act 2005;13:198-209.

52 Toraman A, Yildirim NU: The falling risk and physical fitness in older people. Arch Gerontol Geriatr 2010;51: 222-226.

53 Hesseberg K, Bentzen H, Bergland A: Reliability of the Senior fitness test in community-dwelling older people with cognitive impairment. Physiother Res Int 2015;20:37-44.

54 Shulman KI: Clock-drawing: is it the ideal cognitive screening test? Int J Geriatr Psychiatry 2000;15:548-561.

-55 Strauss E, Sherman EMS, Spreen 0: A Compendium of Neuropsychological Tests: Administration, Norms, and Commentary. Oxford, Oxford University Press, 2006.

56 Reitan RM, Wolfson D: The Halstead-Reitan Neuropsychological Test Battery: Theory and Clinical Interpretation. Tucson, Neuropsychology Press, 1993.

57 Welsh KA, Butters N, Mohs RC, Beekly D, Edland S, Fillenbaum G, Heyman A: The Consortium to Establish a Registry for Alzheimer's Disease (CERAD). V. A normative study of the neuropsychological battery. Neurology 1994;44:609-614.

-58 Aggarwal NT, Wilson RS, Beck TL, Bienias JL, Bennett DA: Motor dysfunction in mild cognitive impairment and the risk of incident Alzheimer disease. Arch Neurol 2006;63:1763-1769.

59 Blankevoort CG, van Heuvelen MJ, Boersma F, Luning H, de Jong J, Scherder EJ: Review of effects of physical activity on strength, balance, mobility and ADL performance in elderly subjects with dementia. Dement Geriatr Cogn Disord 2010;30:392-402.

60 Boyle PA, Buchman AS, Wilson RS, Leurgans SE, Bennett DA: Association of muscle strength with the risk of Alzheimer disease and the rate of cognitive decline in community-dwelling older persons. Arch Neurol 2009; 66:1339-1344.

61 Brown AD, McMorris CA, Longman RS, Leigh R, Hill MD, Friedenreich CM, Poulin MJ: Effects of cardiorespiratory fitness and cerebral blood flow on cognitive outcomes in older women. Neurobiol Aging 2010;31: 2047-2057.

62 Burns JM, Cronk BB, Anderson HS, Donnelly JE, Thomas GP, Harsha A, Brooks WM, Swerdlow RH: Cardiorespiratory fitness and brain atrophy in early Alzheimer disease. Neurology 2008;71:210-216.

63 Deslandes A, Moraes H, Ferreira C, Veiga H, Silveira H, Mouta R, Pompeu FAMS, Coutinho ESF, Laks J: Exercise and mental health: many reasons to move. Neuropsychobiology 2009;59:191-198.

-64 Forbes D, Forbes SC, Blake CM, Thiessen EJ, Forbes S: Exercise programs for people with dementia. Cochrane Database Syst Rev 2015;4:CD006489.

65 Hogan M: Physical and cognitive activity and exercise for older adults: a review. Int J Aging Hum Dev 2005;60: 95-126.

66 Makizako H, Shimada H, Doi T, Park H, Yoshida D, Suzuki T: Six-minute walking distance correlated with memory and brain volume in older adults with mild cognitive impairment: a voxel-based morphometry study. Dement Geriatr Cogn Disord Extra 2013;3:223-232.

67 Park Y, Bae Y: A comparison of functional fitness and walking speed with cognitive function of facility-dwelling elderly women: a cross-sectional study. J Phys Ther Sci 2012;24:73-76.

68 Volkers KM, Scherder EJ: Physical performance is associated with working memory in older people with mild to severe cognitive impairment. Biomed Res Int 2014;2014:1-10.

-69 Eggermont LH, Milberg WP, Lipsitz LA, Scherder EJ, Leveille SG: Physical activity and executive function in aging: The Mobilize Boston Study. J Am Geriatr Soc 2009;57:1750-1756.

70 Netz Y, Dwolatzky T, Zinker Y, Argov E, Agmon R: Aerobic fitness and multidomain cognitive function in advanced age. Int Psychogeriatr 2011;23:114-124. 
71 Eggermont L, Gavett BE, Volkers KM, Blankevoort CG, Scherder EJ, Jefferson AL, Steinberg E, Nair A, Green RC, Stern RA: Lower-extremity function in cognitively healthy aging, mild cognitive impairment, and Alzheimer's disease. Arch Phys Med Rehab 2010;91:584-588.

72 Liu-Ambrose T, Ahamed Y, Graf P, Feldman F, Robinovitch SN: Older fallers with poor working memory overestimate their postural limits. Arch Phys Med Rehab 2008;89:1335-1340.

-73 Carlson MC, Xue QL, Zhou J, Fried LP: Executive decline and dysfunction precedes declines in memory: The Women's Health and Aging Study II. J Gerontol A Biol Sci Med Sci 2009;64:110-117.

74 Scherder E, Eggermont L, Swaab D, van Heuvelen M, Kamsma Y, de Greef M, van Wijck R, Mulder T: Gait in ageing and associated dementias; its relationship with cognition. Neurosci Biobehav Rev 2007;31:485-497.

75 Hiroyuki S, Uchiyama Y, Kakurai S: Specific effects of balance and gait exercises on physical function among the frail elderly. Clin Rehabil 2003;17:472-479.

76 Littbrand H, Lundin-Olsson L, Gustafson Y, Rosendahl E: The effect of a high-intensity functional exercise program on activities of daily living: a randomized controlled trial in residential care facilities. J Am Geriatr Soc 2009;57:1741-1749.

77 Liu R, Sui X, Laditka JN, Church TS, Colabianchi N, Hussey J, Blair SN: Cardiorespiratory fitness as a predictor of dementia mortality in men and women. Med Sci Sports Exerc 2012;44:253-259.

-78 Reisberg B, Kenowsky S, Franssen EH, Auer SR, Souren LE: Towards a science of Alzheimer's disease management: a model based upon current knowledge of retrogenesis. Int Psychogeriatr 1999;11:7-23. 